\title{
DISCURSO DE BOLSONARO NA ONU, EM 2019: A FORÇA DOS MITEMAS E A VERDADE DOS MITOS
}

\author{
Elza Kioko Nakayama Nenoki do Couto-kiokoelza@gmail.com \\ Universidade Federal de Goiás, UFG, Goiânia, Goias, Brasil; Bolsista de Produtividade em Pesquisa do CNPq - Nível 2; \\ http://orcid.org/0000-0002-0987-8448
}

\begin{abstract}
Antonio Busnardo Filho - antonio.busnardo@univag.edu.br Centro Universitário Várzea Grande, UNIVAG, Várzea Grande, Mato Grosso, Brasil; http://orcid.org/0000-0001-8454-

\begin{abstract}
RESUMO: Os discursos políticos e midiáticos contemporâneos acerca da percepção e da interação do ser humano com o meio ambiente apresentam conotações pouco claras sobre a preocupação com a sustentabilidade e com a manutenção da saúde do planeta. Diante dessa percepção e considerando que o homem só apreende a natureza por meio do símbolo, o objetivo dessa pesquisa é investigar como os aspectos simbólicos e míticos são mobilizados para construir os discursos recorrentes acerca da Amazônia. Analisaremos o discurso proferido por Bolsonaro na Assembleia-Geral da ONU, em setembro de 2019. A análise, fundamentada na mitocrítica (Gilbert Durand), aponta para o mito diretor de Maha-Maya ou Maya, a Deusa da Ilusão, no hinduísmo. O véu da ilusão perpassa o discurso do presidente brasileiro naquilo que diz respeito ao novo e ao ressurgimento do Brasil. No entanto, é preciso considerar que o ressurgimento traz um sentido de morte, desvelando o Deus Antaka - Yama -, o Deus da morte. $\mathrm{O}$ discurso do presidente vem permeado de um desejo de destruição para implementar um sonho pessoal, distante dos anseios da maioria da nação, desvelando as Erínias, o terceiro grupo das Deusas Cinzentas (além das Moiras e das Gréias), de nomes Aleto (a que nunca acaba), Tisífone (retaliação) e Megera (raiva); deusas que podem ser invocadas pelo nome de Erinis (espírito de cólera e de vingança); é possível dizer que na fala presidencial, em seu discurso proferido na ONU, ou nas suas apresentações cotidianas, inclusive no seu Twitter, há o sentido de vingança, retaliação e raiva.
\end{abstract}

PALAVRAS-CHAVE: Imaginário; Mitocritica; Discurso; Meio ambiente.

\section{INTRODUÇÃO}

O atual governo brasileiro tem sido marcado por um discurso político que valoriza pessoas com pensamentos e comportamentos agressivos contra outras pessoas, contra outros países e contra a natureza. Essa forma de encarar as coisas representa uma parte significativa da população brasileira, que se vê refletida nas falas e nos comportamentos do presidente Jair Bolsonaro. Político de extrema direita, ele ascendeu ao governo assumindo posicionamentos abertamente misóginos, racistas e pró-violência. Em relação ao meio ambiente, ainda no período de campanha eleitoral, no segundo semestre de 2018, ele já declarava abertamente que iria extinguir os órgãos de fiscalização ambiental e fundir o Ministério do Meio Ambiente ao Ministério da Agricultura, o que deixava explícito a concepção que ele tinha acerca de como o meio ambiente deveria ser tratado politicamente em sua gestão.

Logo no primeiro semestre de 2019, tivemos muitos exemplos do descaso desse governo em relação às questões ambientais, como: a luta constantemente travada pelo Ministro do Meio Ambiente, 
Ricardo Salles, contra as Organizações Não-Governamentais (ONGs) e os ativistas que atuam na preservação no meio ambiente; a exoneração de 21 dos 27 superintendentes regionais do Instituto Brasileiro do Meio Ambiente e dos Recursos Naturais Renováveis (IBAMA); os ataques do Ministro do Meio Ambiente, Ricardo Salles, ao funcionamento do Fundo Amazônia, mantido majoritariamente por doações estrangeiras; a proposta de transformar o município de Angra dos Reis, no Rio de Janeiro, uma área de grande importância ecológica, em uma Cancún Brasileira; o bloqueio de $95 \%$ do orçamento que seria destinado à implantação de medidas e políticas para o combate das mudanças climáticas; a liberação de cerca de 380 agrotóxicos no país, sendo que pelo menos 14 deles são proibidos em outros países por conta do alto nível de toxicidade, uma vez que eles comprovadamente, causam cânceres e vários outros tipos de doenças.

Os posicionamentos assumidos pelo governo atual vão contra todo o caminhar dos países que se preocupam com a questão da sustentabilidade e da manutenção da saúde do planeta. Veiculadas por todos os tipos de mídia, nacionais e internacionais, e pelas redes sociais, as notícias acerca da depredação ambiental no Brasil ecoam, sempre com o mesmo teor de crítica. Elas apontam um alto grau de destruição técnica, moral e ética em uma fala que deveria ser de proteção. Indicam, também, a desvalorização do território amazônico e dos povos que "inventaram” a floresta amazônica, os povos indígenas; tudo em prol dos madeireiros e dos criadores de gado. A fauna e a flora e todo o ecossistema é alterado em troca de lucros e de investimentos que podem ser feitos em outras áreas do país, como o Centro-Oeste, por exemplo.

Esse desdém pela preservação ambiental e pela sustentabilidade levou à crise dos incêndios na Floresta Amazônia em agosto de 2019, com o registro de mais de 30 mil focos de queimada, quase o triplo do que havia sido registrado em 2018, no mesmo período, segundo dados Programa de Queimadas do Instituto Nacional de Pesquisas Espaciais (INPE). Diante da comoção nacional e internacional face a tamanha destruição, Bolsonaro proferiu um discurso na Assembleia-Geral da Organização das Nações Unidas (ONU), em setembro de 2019, que tinha como foco a questão ambiental, centrada especificamente na Floresta Amazônica. Esse é o texto que será analisaremos aqui. O objetivo desse artigo volta-se para um estudo mitocrítico do discurso de Bolsonaro, analisando-o em seus aspectos arquetípicos, simbólicos e míticos. Para tanto, torna-se necessário assumir posições epistemológicas, metodológicas e teóricas inerentes aos estudos sobre o Imaginário proposto por DURAND (1981). Por meio dessa análise, buscaremos desvelar as intenções subliminares da fala e compreender o mito reitor contido na fala presidencial. 


\section{O ECOSSISTEMA FLORESTA AMAZÔNICA}

A Amazônia, maior floresta tropical do mundo, não deve ser tomada levianamente como um fato dado. É preciso entendê-la como um grande jardim, plantado, formado e cuidado pelos povos originários. Esse jardim começou a ser plantado há mais de 8.000 anos, semelhante ao procedimento usado no Egito Antigo, conforme explica Levis e outros (2017). Primeiro eram selecionadas as plantas com características que poderiam ser úteis ao homem; em um segundo momento, era feita a propagação dessas espécies. Essas espécies vegetais domesticadas pelas civilizações pré-colombianas começaram a ser cultivadas em pátios e jardins, por meio de um processo quase intuitivo de seleção e, atualmente, são as mais dominantes na região.

Nesse período de milhares de anos, a natureza aprendeu quais são as espécies mais propícias ao meio ambiente amazônico, criando uma grande rede química que estrutura a vida da região em um processo metabólico, como o de todas as formas de vida. Conforme Capra (2003) explica:

É essa a chave da definição sistêmica da vida: as redes vivas criam ou recriam a si mesmas continuamente mediante a transformação ou a substituição dos seus componentes. Dessa maneira, sofrem mudanças estruturais contínuas ao mesmo tempo que preservam seus padrões de organização, que sempre se assemelham a teias. (CAPRA 2003, p. 18)

Se a vida se dá em teia, se há uma rede de comunicação entre os seres vivos, é óbvio que qualquer alteração no sistema causará um desastre, pois mudará o ciclo de vida do sistema, que demorará o tempo da eternidade da natureza para se recompor e para aprender novamente a ser um sistema. A substituição brusca de componentes rompe o processo natural da autopoiesis, característica fundamental da vida, aquilo que permite a autonomia do ser vivo (Maturana; Varela, 2001).

Nesse sentido, é possível perceber a nefasta fala do poder instituído no Brasil e o desconhecimento de causa de seus representantes. As discussões acerca do meio ambiente ganham vulto em um universo paralelo das infovias e das redes sociais, numa realidade virtual que distancia o indivíduo, cada vez mais, dos problemas da vida comum, do dia a dia das ruas, da banalidade cotidiana, encapsulando-o como se em um “universo sem mal algum”, de onde ele pode falar, analisar, criticar, mas sem se envolver; uma vida sem consequências. A questão é que a vida se interliga, também, nos seus processos de comunicação e, de tanto se ouvir mentiras e de tanto se dizerem mentiras, as atitudes perniciosas se colocam como princípios de mudança e se espalham, em rede, para a sociedade, mudando o comportamento dos indivíduos, deixando-os parvos. 
O mais importante e que os governos - principalmente os totalitários/autoritários, como Brasil, EUA, Coreia do Norte, por exemplo - não entendem é que há uma ordem que se sobrepõe a esse diminuto poder, que é uma organização sistêmica da Natureza, como demonstram Maturana e Varela (2001), Capra (2003) e até mesmo Hillman (1997), evidenciando que, para restabelecer o equilíbrio do mundo, às vezes, o mal é necessário. Hillman (1997) aponta a necessidade da semente podre como processo de crescimento e amadurecimento da sociedade mundial, caso do nazismo e dos regimes autoritários da época. No entanto, não é possível que se tenha que repetir essa situação sem nenhum propósito e de forma tão desastrosa. Se assim for, por que não há uma resposta mundial ao fato? Por mais que a Amazônia seja de soberania nacional, ela faz parte de uma organização sistêmica do planeta. Tanto que ela é responsável por $20 \%$ do oxigênio é produzido na atmosfera terrestre. Não é possível que por causa dessa soberania, a mídia do país se cale ou faça vistas grossas ante tal absurdo, sendo conivente com a situação. Em que ponto do discurso está a fala perdida? Será que a língua se desvinculou do meio e o povo desaprendeu a fala da convivência?

\section{MITOCRÍTICA}

A investigação empreendida por meio da análise mitocrítica tem o propósito de desvelar o texto - sempre apresentado parcialmente -, encontrando o seu centro, o seu núcleo ou, ainda, o "ser pregnante do texto" que olha para o leitor como que querendo encantá-lo e que pertence ao domínio do mito. Estes sinais que olham para o leitor são as homologias, que pertencem às mesmas famílias dos significados, são os adjetivos e os substantivos, adjetivos que qualificam os substantivos dando-lhes cor, uma "cor psíquica" (Durand, sd). A leitura do texto faz-se, então, por grupos de palavras que podem ir do "substantivo com seu atributo até um fraseado mais longo onde o verbo intervém” (DURAND, 1981, p. 83), formando conjuntos coalescentes possíveis de serem classificados. Esses conjuntos definem o nível de leitura do texto, buscando sempre o "mito" que o constitui, na menor unidade que o representa, o mitema. O mitema é o ponto forte da narrativa, a menor unidade representativa do mito e apresentase em número limitado. É por meio do mitema que se torna possível fazer uma análise sincrônica do texto. O número limitado de mitemas faz com que eles sejam preenchidos pelos mitos reitores, que se apresentam com constância em uma determinada época e cultura.

De acordo com Durand (1998), é possível discernir grosseiramente seis “níveis” na narrativa: 1) no título, que será significativo se for redundante na obra de um autor; 2) nas obras de pequenas dimensões que têm intenções muito indicativas; 3) nas obras de grandes dimensões é que a mitocrítica age eficazmente; 4) na obra completa de um autor, com abrangência de quinze a setenta anos, as redundâncias temáticas e dramáticas manifestam-se mais claramente; 5) em uma obra completa que incita 
a análise de "épocas históricas" de uma cultura, destacando os seus mitos; essa análise das épocas encaminha a uma reflexão no tempo e no espaço cultural das "bacias semânticas", que se constroem em seis fases determinantes da gênese e do declínio do mito; 6) se o terreno de investigação abarca um espaço e um tempo imemoriais, pode-se descobrir a dinâmica de um mito em todos os seus matizes, em toda a sua amplitude. Como é possível observar, quanto mais amplo o terreno de informação, mais completa e frutífera será a mitocrítica.

Nestes seis níveis do texto é que se procederá a mitocrítica, cujo primeiro passo implica encontrar unidades (mitemas) na narrativa diacrônica da obra, no próprio tempo da obra, mesmo que este tempo seja duplo, o tempo da leitura e o tempo figurado. Em seguida, deve-se observar a redundância e a determinação do mitema, apresentando os "pacotes de imagens" ou "constelações" com traços comuns que reenviam para os mesmos significados. São estes os indicadores do mito. Geralmente, esses "pacotes de imagens" não ultrapassam quatro ou cinco, porque, como já foi dito, os mitemas têm uma estrutura muito simples. Após a separação dos mitemas, deve-se retornar ao texto e, numa leitura diacrônica, anotar as sequências que interessam à mitocrítica. Assim, na diacronia da narrativa, sobrepõem-se os mitemas, gerando uma sincronicidade e uma leitura com dupla entrada.

A mitocrítica é uma análise subjetiva, porque o texto não é objetivo e toda leitura é uma criação subjetiva, pois toda narrativa tem vários significados. Deve-se, portanto, correr o risco, já que a narrativa nasce de uma subjetividade profunda e, por esse motivo, estar atento àquilo que no texto olha para $\mathrm{o}$ leitor, ao "sinal", e que leva em conta a homologia ou significados da mesma família. Isto é, um substantivo e um adjetivo, já que o atributo qualificativo dá a cor psíquica, como aponta Durand (sd). Enfim, "chegados assim a uma leitura por grupos de palavras mais ou menos grandes, que podem ir do simples substantivo com seu atributo até um fraseado mais longo onde o verbo intervém, obtemos conjuntos coalescentes e que podemos determinar e classificar" (DURAND, 1981, p. 83). Esses grupos de palavras gravitam em torno do verbo, de sua ação expressa, permitindo uma interpretação diferente, que, na esteira da "qualificação" resultante da repetição - a metábole -, caracteriza o mito e evidencia a qualidade semântica da mitocrítica, encaminhando-se a uma mitanálise. Como nosso foco recai apenas sobre a mitocrítica, finalizaremos esse apanhado teórico por aqui.

\section{ANÁLISE DOS DADOS}

Após uma necessária explicitação do método proposto pela mitocrítica, passemos à análise do discurso presidencial.

\section{[Trecho 1]}

Travessias, Cascavel, v. 14, n. 1, p. 121-139, jan./abr. 2020. http://www.unioeste.br/travessias 
Senhor Presidente, da Assembleia Geral, Tijjani Muhammad-Bande,

Senhor Secretário-Geral da ONU, António Guterres,

Chefes de Estado, de Governo e de Delegação,

Senhoras e Senhores,

Apresento aos senhores um novo Brasil, que ressurge depois de estar à beira do socialismo. Um Brasil que está sendo reconstruído a partir dos anseios e dos ideais de seu povo. No meu governo, o Brasil vem trabalhando para reconquistar a confiança do mundo, diminuindo o desemprego, a violência e o risco para os negócios, por meio da desburocratização, da desregulamentação e, em especial, pelo exemplo.

Meu país esteve muito próximo do socialismo, o que nos colocou numa situação de corrupção generalizada, grave recessão econômica, altas taxas de criminalidade e de ataques ininterruptos aos valores familiares e religiosos que formam nossas tradições.

O enunciador começa o discurso se reportando às autoridades presentes na $\mathrm{ONU}$, o adjetivo novo anteposto ao substantivo Brasil nos remete à ideia de um país diferente. O prefixo re- em ressurge, reconstruido e reconquistar reforça a noção de um novo Brasil, apresentando a ideia de reabilitação como estratégia de gestão governamental. Por meio do conhecimento de mundo, podemos presumir, então, que teremos novas ações governamentais em relação ao ecossistema natural, mental e social do Brasil. Outro prefixo presente nesse trecho é o des- das palavras desemprego, desburocratização e desregulamentação, presentes em um enunciado que nos leva a pensar que, nesse novo Brasil, não teremos tantas pessoas desempregadas, submetidas a tantas regras e burocracias.

O uso dos prefixos re- e des- no discurso de Bolsonaro nos remete ao texto de Paul Lafargue (2019) em que ele aborda a intensificação no uso dos prefixos re- e des-durante e após a Revolução Francesa (1789-1799). Eles eram mobilizados para representar o fato de que os revolucionários queriam desfazer tudo que tinha a ver com o velho regime e refazer tudo em consonância com os ideais da Revolução. Esse texto está disponível em português (Lafarque, 2019). Morin (2001) mostrou o papel do prefixo re- na representação da evolução cíclica da natureza e da cultura, aí incluída a língua. Ele não falou de des- que, na verdade, faz parte desse ciclo. O prefixo des-, conforme aponta Couto (2003), traz aspectos semânticos que apontam para a noção de des- arranjo, de des- harmonia, o que nos remete para a ideia de destruição.

Como Couto (2003) bem demonstra em sua análise, os prefixos des- e re- representam o ciclo da natureza, da vida. Nesse sentido, podemos dizer que o mitema apresentado aqui é o de renovação de um espaço natural e social que se apresentava de uma maneira não desejável, que busca ressurgir de uma maneira positiva com o intuito de atender aos anseios de sua população. $\mathrm{O}$ mitema da renovação vem sempre acompanhado de um mitema de destruição, porque, ao renovar, destrói-se o que já existia. Temse, assim, o mitema de renovação/destruição.

Nesse trecho, também aparece o pronome possessivo meu junto ao substantivo país, algo reincidente em várias partes do discurso. Não se faz necessário qualquer explicação, por ser muito clara 
a intenção: se é meu, posso fazer o que quiser, sem ter que dar satisfações. Há aí, a imposição autoritária daquele que possui. No entanto, ele ignora que não é só ele, o presidente, que pode dizer do Brasil "é meu”. O país é de todos os brasileiros e, com certeza, os milhões de brasileiros que não votaram em Bolsonaro discordam do que está sendo apresentado como verdade pelo discurso dele.

\begin{abstract}
[Trecho 2]
Senhorita YSANY KALAPALO, agora vamos falar de Amazônia. Em primeiro lugar, meu governo tem um compromisso solene com a preservação do meio ambiente e do desenvolvimento sustentável em benefício do Brasil e do mundo. O Brasil é um dos países mais ricos em biodiversidade e riquezas minerais. Nossa Amazônia é maior que toda a Europa Ocidental e permanece praticamente intocada. Prova de que somos um dos países que mais protegem o meio ambiente.
\end{abstract}

Ao usar o vocativo Senhorita Ysany Kalapalo, o enunciador atribui a uma pessoa o papel de interlocutor, restringindo a ela o direito de resposta sobre um assunto que é de interesse geral. O pronome pessoal men, o substantivo governo e o adjetivo solene nos remetem à ideia do comprometimento relevante e sério em relação à preservação da natureza, sendo esta representada pela Amazônia, em uma relação metonímica, na qual a parte é tomada pelo todo. A descrição de um espaço natural e social - país Brasil - que possui um ecossistema biológico muito rico é acompanhada pelo pronome possessivo Nossa anteposto ao substantivo Amazônia, o que estabelece uma relação de posse da Amazônia pelos brasileiros. Assim, esse trecho enfatiza que a Amazônia tem dono, os brasileiros, que são seus protetores. Essa proteção seria tamanha que, para o enunciador, a floresta permanece intacta.

O discurso de Bolsonaro omite dados importantes acerca do desmatamento na Amazônia. Segundo dados do Projeto de Monitoramento do Desmatamento na Amazônia Legal por Satélite (Prodes), do Instituto Nacional de Pesquisas Espaciais, o desflorestamento nessa região cresceu cerca de 30\% entre agosto de 2018 e julho de 2019 (INPE, 2019). Dados recentes de um estudo realizado pela Universidade de Oklahoma apontam que, entre 2000 e 2017, cerca de 400 mil km² foram devastados (Yuanwei Qin et al., 2019), uma área equivalente à Alemanha. Em um alerta publicado na revista científica Science Advandes, Lovejoy e Nobre (2018) apontam que, caso o desmatamento na floresta amazônica não cesse, essa região vai se transformar, nas próximas décadas, em uma grande savana bastante degradada. Esses dados apontam para um silenciamento acerca do que de fato ocorre no Brasil e indicam que nós somos um dos países que mais provoca o desequilíbrio do ecossistema.

O direcionamento da fala a uma única pessoa aponta para a anulação dos outros ouvintes, demonstrando, claramente, o desrespeito e a pouca importância que o Outro/Outrem tem para o interlocutor. Fala-se para um ouvinte escolhido, desconsiderando os demais ouvintes. A fala constrói, 
também, o sentido de um Estado permanente e ideal, sem problemas, assunto que não cabe ser discutido aqui. Tem-se, neste trecho, o mitema da ilusão.

\section{[Trecho 3]}

Nesta época do ano, o clima seco e os ventos favorecem queimadas espontâneas e criminosas. Vale ressaltar que existem também queimadas praticadas por índios e populações locais, como parte de sua respectiva cultura e forma de sobrevivência.

Neste trecho temos um adjunto adverbial de tempo, um sujeito clima seco e ventos que são responsáveis pelas queimadas espontâneas, ou seja, as queimadas são fatos naturais que ocorrem com mais frequência em determinadas épocas do ano. Entretanto, conforme Brown (2003, p 112) esclarece, “intactas, florestas tropicais não queimam, mas florestas enfraquecidas pela atividade madeireira ou queimadas agrícolas se tornam vulneráveis ao fogo". Além disso, este enunciado apresenta um sujeito elíptico para as queimadas criminosas. $\mathrm{Na}$ segunda oração, os indígenas e as populações também são culpabilizados pelas queimadas. Ao usar o advérbio de inclusão também, o presidente se trai, pois, esta palavra deixa implícito que a maioria das queimadas tem outra origem: as causadas por "índios e populações locais" seriam apenas mais algumas que se juntariam às inúmeras outras (as criminosas), sobre as quais ele se silencia.

Como é possível perceber, temos um destaque dos elementos da natureza e dos índios e populações locais como os responsáveis pela perda de um pequeno espaço da Amazônia. Novamente, o enunciador recorre ao sentido da destruição como agente natural para disfarçar a responsabilidade de outrem ou a própria responsabilidade, enquanto chefe da Nação. Há um véu de ilusão e uma destruição consentida, o que nos remete, novamente, para o mitema da destruição/ilusão como condutor da fala.

\section{[Trecho 4]}

Problemas qualquer país os tem. Contudo, os ataques sensacionalistas que sofremos por grande parte da mídia internacional devido aos focos de incêndio na Amazônia despertaram nosso sentimento patriótico.

É uma falácia dizer que a Amazônia é patrimônio da humanidade e um equívoco, como atestam os cientistas, afirmar que a nossa floresta é o pulmão do mundo.

Valendo-se dessas falácias, um ou outro país, em vez de ajudar, embarcou nas mentiras da mídia e se portou de forma desrespeitosa, com espírito colonialista.

Questionaram aquilo que nos é mais sagrado: a nossa soberania!

Um deles por ocasião do encontro do G7 ousou sugerir aplicar sanções ao Brasil, sem sequer nos ouvir. Agradeço àqueles que não aceitaram levar adiante essa absurda proposta.

Em especial, ao Presidente Donald Trump, que bem sintetizou o espírito que deve reinar entre os países da ONU: respeito à liberdade e à soberania de cada um de nós.

No Trecho 5, é possível notar implícitos que remetem para uma permissão e conivência com a destruição. Ao mesmo tempo, percebe-se uma visão equivocada e ingênua acerca da questão da soberania, 
que estabelece um contraponto com a subserviência em relação aos Estados Unidos. Claramente, percebe-se que os mitemas da destruição/ilusão vêm escondidos na palavra falácia, que deixa claro a posição dele em relação à Amazônia ser um patrimônio da humanidade. O que ele está falando é que ela não é da humanidade, mas do Brasil, ainda que, de modo geral, as pessoas acreditem nele. É falácia, também, que a Amazônia é o pulmão do mundo. Ele desautoriza o discurso científico, dizendo que ele é falacioso. Quem vem falando que a Amazônia é patrimônio ambiental e o pulmão do mundo, são os cientistas. É um ataque direto a eles. Ao fazer isso, de novo, ele omite diversos estudos que apontam a importância da Amazônia para o ecossistema mundial. A destruição/ilusão dele é de que esse discurso é falso, quando de fato não o é e ao dizer que ele é falso, ele é conivente com o desmatamento da região.

\begin{abstract}
[Trecho 5]
Hoje, 14\% do território brasileiro está demarcado como terra indígena, mas é preciso entender que nossos nativos são seres humanos, exatamente como qualquer um de nós. Eles querem e merecem usufruir dos mesmos direitos de que todos nós.

Quero deixar claro: o Brasil não vai aumentar para $20 \%$ sua área já demarcada como terra indígena, como alguns chefes de Estados gostariam que acontecesse.

Existem, no Brasil, 225 povos indígenas, além de referências de 70 tribos vivendo em locais isolados. Cada povo ou tribo com seu cacique, sua cultura, suas tradições, seus costumes e principalmente sua forma de ver o mundo.
\end{abstract}

Neste trecho, ao mesmo tempo em que é dito que os indígenas são seres humanos e que têm os mesmos direitos dos homens brancos, fica claro que esse direito é restrito, posto que a área de reserva das terras indígenas não será ampliada. Nota-se, também, a mentira disfarçada e a exclusão do mundo dos "homens brancos", quando ele aponta que cada povo tem sua cultura e tradições. Há um claro sentido de isolamento, corroborado pelas ideias de que não há necessidade de aumentar as terras indígenas e de que eles devem ficar, com seus hábitos, exatamente onde estão. O mitema realizado aqui é o da mentira e da exclusão, ou melhor, do isolamento, entendido como uma "prisão cuidada".

Nesta fala, o essencial é ignorado, a dimensão histórica que configura a relação entre homens brancos e indígenas. Omite-se o fato - não se trata de interpretação, de achismo - de que os índios são os habitantes originais das terras em que se encontram e que os brancos são os verdadeiros usurpadores, desde 1500. Esse fato é solene e convenientemente invisibilizado no discurso do presidente brasileiro.

\footnotetext{
[Trecho 6]

A visão de um líder indígena não representa a de todos os índios brasileiros. Muitas vezes alguns desses líderes, como o Cacique Raoni, são usados como peça de manobra por governos estrangeiros na sua guerra informacional para avançar seus interesses na Amazônia.

Infelizmente, algumas pessoas, de dentro e de fora do Brasil, apoiadas em ONGs, teimam em tratar e manter nossos índios como verdadeiros homens das cavernas.
}

Travessias, Cascavel, v. 14, n. 1, p. 121-139, jan./abr. 2020.

http://www.unioeste.br/travessias 
É possível perceber, claramente, no Trecho 6, o mitema da mentira e da destruição, voltados contra uma liderança indígena, o Cacique Raoni. Levianamente, fala em termos genéricos, sem apresentar dados, e desrespeita não só um líder, mas um senhor de idade avançada que ainda luta em prol da preservação, da integridade e identidade de seu povo, o que requer, em primeiro lugar, o direito ao seu território. Além disso, o mitema da mentira também recai sobre a crítica do enunciador em relação ao uso de indígenas como peças de manobra pelos governos, uma vez que ele mesmo chegou à Assembleia-Geral da ONU acompanhado pela indígena Ysani Kalapalo, incluída na comitiva presidencial de última hora.

\begin{abstract}
[Trecho 7]
O Brasil agora tem um presidente que se preocupa com aqueles que lá estavam antes da chegada dos portugueses. O índio não quer ser latifundiário pobre em cima de terras ricas. Especialmente das terras mais ricas do mundo. É o caso das reservas Ianomâmi e Raposa Serra do Sol. Nessas reservas, existe grande abundância de ouro, diamante, urânio, nióbio e terras raras, entre outros.

E esses territórios são enormes. A reserva Ianomâmi, sozinha, conta com aproximadamente $95 \mathrm{mil} \mathrm{km} 2$, o equivalente ao tamanho de Portugal ou da Hungria, embora apenas 15 mil índios vivam nessa área.

Isso demonstra que os que nos atacam não estão preocupados com o ser humano índio, mas sim com as riquezas minerais e a biodiversidade existentes nessas áreas.
\end{abstract}

Novamente, é notada a desfaçatez na fala presidencial, quando aponta a sua preocupação com os indígenas e, logo em seguida, ressalta toda a riqueza das terras Ianomâmi. Mais uma vez, temos o mitema da mentira e da ilusão, numa tentativa de enganar os ouvintes, uma vez que o verdadeiro interesse dele não está no bem-estar dos indígenas, mas na posse das terras deles. O presidente ignora o fato de que os índios têm outra cultura, outros valores e que atuam sobre o meio ambiente de forma diferenciada. A existência de "abundância de ouro, diamante, urânio, nióbio", para eles, não é mais importante do que a vegetação, a floresta, os rios, as águas, os animais para caça, os peixes para a pesca. Eles sabem que ninguém se alimenta de "ouro, diamante, urânio, nióbio".

O mitema da mentira e ilusão também aparece na fala do presidente quando ele mobiliza o advérbio de tempo agora para apontar que nenhum governo anterior se preocupou com a causa indígena. Esse enunciado se contrapõe ao fato de que todos os governos da jovem democracia brasileira, desde Fernando Collor (1990 - 1992) até Dilma Rousseff (2011 - 2016), demarcaram territórios indígenas, ao contrário do que pretende fazer o governo atual, que deixou bem claro em seu discurso que não cederá mais nenhum pedaço de terra aos indígenas.

\title{
[Trecho 8]
}

Para mostrar aos senhores que não existe uma autoridade única entre os índios eu quero ler uma carta das comunidades indígenas endereçadas aos senhores:

"O Grupo de Agricultores Indígenas do Brasil, formado por diversas etnias, e com representantes por todas as unidades da federação, que habitam uma área mais de 30 
milhões de hectares do território brasileiro, vem respeitosamente perante a sociedade brasileira endossar total e irrestrito apoio à indígena Ysani Kalapalo, aqui presente, do Parque Indígena do Xingu, do Mato Grosso, para que a mesma possa da Assembleia Geral das Nações Unidas, em Nova York, nos Estados Unidos, externar toda a realidade vivida pelos povos indígenas do Brasil, bem como trazer à tona o atual quadro de mentiras propagado pela mídia nacional e internacional, que insiste em fazer dos povos indígenas do Brasil uma reserva de mercado sem fim, atendendo aos interesses estrangeiros de países que ainda enxergam o Brasil como uma colônia sem regras e sem soberania.

O Brasil possui 14\% de seu território nacional regularizado em terras indígenas, e muitas comunidades estão sedentas para que o desenvolvimento desta parte do Brasil finalmente ocorra sem amarras ideológicas ou burocráticas. Isso facilitará o alcance de uma maior qualidade de vida nas áreas de empreendedorismo, saúde e educação.

Uma nova política indigenista no Brasil é necessária. O tempo urge.

Medidas arrojadas podem e devem ser incentivadas na busca pela autonomia econômica dos indígenas. Certamente, que se um conjunto de decisões vier neste sentido, poderemos vislumbrar um novo modelo para a questão indígena brasileira.

Um novo tempo para as comunidades indígenas é fundamental, a situação de extrema pobreza em que se encontram, sobrevivendo tão somente do Bolsa Família e de cestas básicas nunca representou dignidade e desenvolvimento.

A realidade ora posta impõe que o mundo na arena da Assembleia das Nações Unidas possa reconhecer nossos desejos e aspirações na voz da indígena Ysani Kalapalo que transmitirá o real quadro do meio ambiente e das comunidades indígenas brasileiras.

Portanto, Ysani Kalapalo goza da confiança e do prestígio das lideranças indígenas interessadas em desenvolvimento, empoderamento e protagonismo, estando apta para representar as etnias relacionadas'.

Acabou o monopólio do senhor Raoni”. [Este trecho é muito longo, com pouco comentário. Incluir apenas as passagens que são comentadas].

Neste trecho, temos uma carta atribuída pelo enunciador às comunidades indígenas. Há, aqui, a tentativa de descaracterizar a representatividade do cacique Raoni, liderança indígena que atua em nome dos povos originários há bastante tempo, e favorecer Ysani Kalapalo, que aparece no cenário recentemente, apoiando o discurso presidencial. Novamente, temos o mitema da mentira e ilusão quando, por meio de uma construção metonímica, o presidente busca excluir da sua prática governamental todos os povos indígenas que não estão de acordo com a sua política, desvalorizando as demandas deles e dando espaço apenas para aqueles que coadunam com a sua visão. Há, também, a tentativa de desviar a atenção dos outros países acerca do que ele pretende fazer e faz: em vez de se preocupar com os índios, preocupa-se com as riquezas existentes nas terras destes.

\section{[Trecho 9]}

A Organização das Nações Unidas teve papel fundamental na superação do colonialismo e não pode aceitar que essa mentalidade regresse a estas salas e corredores, sob qualquer pretexto.

Não podemos esquecer que o mundo necessita ser alimentado. A França e a Alemanha, por exemplo, usam mais de $50 \%$ de seus territórios para a agricultura, já o Brasil usa apenas $8 \%$ de terras para a produção de alimentos.

$61 \%$ do nosso território é preservado!

Travessias, Cascavel, v. 14, n. 1, p. 121-139, jan./abr. 2020.

http://www.unioeste.br/travessias 
Nossa política é de tolerância zero para com a criminalidade, aí incluídos os crimes ambientais.

Neste trecho, percebe-se, claramente, as mentiras sobre um país que nunca existiu e um país que nunca existirá. A tentativa de criar a ilusão de um país hospitaleiro, com responsabilidade social, que respeita os direitos humanos é fortemente enganosa, considerando-se fatos paralelos que apontam para a violência no contexto brasileiro, como o assassinato de Marielli Franco, a execução do músico Evaldo dos Santos com 80 tiros disparados contra o carro dele, a morte de Ágatha Félix, uma das cinco crianças atingidas por bala perdida, no Rio de Janeiro, em 2019, e o assassinato de Lucas, de 14 anos, que tem sido atribuído a policiais militares. Além disso, a tolerância zero do governo Bolsonaro em relação à criminalidade não se estende àqueles que fazem parte do seu circuito de afetos. Os mitemas de mentira e ilusão, nesse sentido, são marcantes.

\footnotetext{
[Trecho 10]

Quero reafirmar minha posição de que qualquer iniciativa de ajuda ou apoio à preservação da Floresta Amazônica, ou de outros biomas, deve ser tratada em pleno respeito à soberania brasileira.

Também rechaçamos as tentativas de instrumentalizar a questão ambiental ou a política indigenista, em prol de interesses políticos e econômicos externos, em especial os disfarçados de boas intenções.

Estamos prontos para, em parcerias, e agregando valor, aproveitar de forma sustentável todo nosso potencial.

O Brasil reafirma seu compromisso intransigente com os mais altos padrões de direitos humanos, com a defesa da democracia e da liberdade, de expressão, religiosa e de imprensa. É um compromisso que caminha junto com o combate à corrupção e à criminalidade, demandas urgentes da sociedade brasileira.
}

O uso do re- afirmar, nos leva a pensar que Bolsonaro sempre teve a posição de ajudar e apoiar não só a preservação da Floresta Amazônia como também de outros biomas, ou seja, temos um presidente que se mostra a favor de um desenvolvimento com envolvimento. Isso nos leva a pensar numa incoerência entre discurso e prática. Ele critica as tentativas de instrumentalizar a causa ambiental ou indígena, mas faz isso. Fala em parcerias, mas destaca ferrenhamente a soberania nacional - algo do tipo, você pode brincar, mas a bola é minha. Reafirma o compromisso com os direitos humanos e a defesa de liberdade de expressão e de imprensa, mas está o tempo inteiro atacando a mídia.

\section{[Trecho 11]}

Hoje o Brasil está mais seguro e ainda mais hospitaleiro. Acabamos de estender a isenção de vistos para países como Estados Unidos, Japão, Austrália e Canadá, e estamos estudando adotar medidas similares para China e India, dentre outros.

Com mais segurança e com essas facilidades, queremos que todos possam conhecer o Brasil, e em especial, a nossa Amazônia, com toda sua vastidão e beleza natural. 
Ela não está sendo devastada e nem consumida pelo fogo, como diz mentirosamente a mídia. Cada um de vocês pode comprovar o que estou falando agora.

Não deixem de conhecer o Brasil, ele é muito diferente daquele estampado em muitos jornais e televisões!

Reafirmo nossa disposição de manter contribuição concreta às missões da ONU, inclusive no que diz respeito ao treinamento e à capacitação de tropas, área em que temos reconhecida experiência.

Também estamos ansiosos para visitar nossos parceiros, e amigos, na África, na Oceania e na Europa.

Senhoras e Senhores,

O Brasil que represento é um país que está se reerguendo, revigorando parcerias e reconquistando sua confiança política e economicamente.

Com humildade e confiante no poder libertador da verdade, estejam certos de que poderão contar com este novo Brasil que aqui apresento aos senhores e senhoras.

Agradeço a todos pela graça e glória de Deus!

Meu muito obrigado"

Neste trecho, são encontradas, repetidas vezes, o adjetivo novo, o pronome possessivo meu e o prefixo re-, elementos linguísticos que indicam uma reconstrução ou uma correção de um passado “errado" e que deve ser apagado da história, como nem pontuou Lafargue (2019) ao analisar o contexto da Revolução Francesa. O adjetivo novo nem sempre se refere a algo inusitado ou nunca visto, como se pretende no discurso. Não há indicações acerca do que seria essa modernidade na fala presidencial e tampouco novidade naquilo que é proposto. Desde o início de sua gestão, é repetido o retorno a um estado de repressão e de "caça" às minorias e aos pobres. E isso não é discurso nonsense, é a fala do poder instituído.

Em relação ao prefixo re-, deve-se dizer que ele nem sempre remete a uma ação positiva, principalmente quando há a tentativa de se recuperar algo ou algum período da história que todos querem esquecer, mas que sempre é louvado pelo presidente, que, inclusive, promove a heroicização de indivíduos que foram, reconhecidamente, torturadores, como o General Brilhante Ustra. Neste caso, o prefixo mais adequado é des-, que permite mostrar que tudo deve ser desfeito, jamais refeito.

Nesse sentido, o adjetivo e o prefixo apontados dão um sentido cíclico na imagem do discurso, mas a passagem não é demonstrada de uma forma orgânica, como consequência de um estado natural dos fatos que seguem os processos de uma ecologia sustentável, como propõe Capra (2003) e Maturana e Varela (2001). O que subjaz a esses elementos da linguagem é simplesmente uma ruptura, que tem como resultado a configuração de um hiato entre fala e fatos. Melhor dizendo, um abismo.

A semiótica discursiva focaliza as contraposições, discutindo o fazer-crer e o crer-verdadeiro como "procedimentos sintáxicos, capazes de dar conta de uma busca interior de verdade, de uma reflexão dialética" (Greimas \& Courtes, 2008, p. 487). Projeta, desse modo, o quadrado semiótico das modalidades, segundo modalidades veridictórias:

$$
\text { Ser }+ \text { parecer }=\text { verdade }
$$




\section{Ser+ não parecer $=$ segredo ou mistério \\ Não ser+parecer $=$ mentira ou ilusão \\ Não ser+ não parecer $=$ falsidade}

Em seu discurso, Bolsonaro parece preocupar-se com a preservação da Amazônia. Contudo, ora subentendido, ora explicito, fica claro que ele não o é. Temos, assim, uma mentira ou a ilusão de acreditar que a preservação será mantida, o que reforça o mitema de mentira e ilusão.

\section{DESTRUIR PARA...}

Considerando a análise e o que aponta Durand (1981) a respeito da mitocrítica, torna-se possível apontar a reincidência de alguns mitemas ao longo do discurso presidencial. A repetição incansável de estruturas linguísticas como o adjetivo novo, as palavras com o prefixo re-, o pronome possessivo men e as palavras que indicam progresso, conforme demonstrou a análise de alguns trechos que se referem à Amazônia - interesse da presente investigação -, indicam um esforço para tentar demonstrar a importância da floresta. Entretanto, esta é constantemente reduzida às riquezas que existem em seu subsolo, ou seja, aos minérios que se encontram atualmente em terras indígenas. O conteúdo da floresta, suas matas, seus rios, sua fauna e as populações humanas que lá habitam, aquilo que mantém esse grande ecossistema vivo e que faz com que ele seja parte de um ecossistema mundial, de uma rede de integração climática planetária, é completamente invisibilizado na fala de Bolsonaro.

O sentido de mantenedor do poder e de reconstrutor do mundo, que nega o existente e propõe algo impossível de acontecer enquanto novo e que encontra no prefixo re- a força da negação do existente, fundamenta-se em mitemas que indicam uma grande ilusão na intenção do locutor. Esses mitemas apontam para Maha-Maya (Zimmer, 1986), ou simplesmente Maya, a Deusa da Ilusão, no hinduísmo, como mito diretor, a Deusa que cria o mundo, juntamente com Brahma. Enquanto Brahma cria o real, Maya cria o ilusório e os sonhos. O véu da ilusão perpassa o discurso presidencial no que diz respeito ao novo e ao ressurgimento do Brasil. Entretanto, ao mesmo tempo em que se pretende o ressurgimento, o renascimento, é preciso considerar que há nisso um sentido de morte, daquilo que põe fim a vida e, portanto, surge o Deus Antaka (Zimmer, 1986), epíteto de Yama, o Deus da morte. Para que o mundo renasça é preciso que ele seja destruído. Nesse sentido, o discurso de Bolsonaro vem permeado de um desejo de destruição de uma realidade vigente com o intuito de implementar um sonho pessoal, distante dos anseios da maioria da nação. A ilusão formada pelo véu das palavras que enganam os que simplesmente aceitam ordens encaminha a realidade para a destruição, a morte, enquanto princípio reorganizador do Brasil. 
Pode-se ampliar a análise para além do discurso e pensar um pouco acerca do desempenho do presidente durante os primeiros meses de seu governo e da atuação da mídia, que a todo instante aponta as incoerências presidenciais. Falamos, portanto, do ethos (hábitos e costumes, єӨos; ou caráter, disposição, costumes, $\left.\eta \eta_{0 \varsigma}\right)$. Considera-se, aqui, a referência ao caráter, conforme se apresenta à Nação - desde a relação com os governos mundiais até as suas falas ao povo brasileiro; num momento violentas/agressivas e em outro, impositivas, depreciativas e violentas. Juntando-se esses aspectos à análise do discurso, entende-se que o mito reitor desvela as Erínias (Kerényi, 2015), o terceiro grupo das Deusas Cinzentas (além das Moiras e das Gréias). Eram mais velhas que os deuses que chegaram com Zeus e tinham serpentes no lugar dos cabelos. Seus nomes eram Aleto (a que nunca acaba), Tisífone (retaliação) e Megera (raiva). Essas deusas podiam ser invocadas juntas e atendiam pelo nome de Erinis (espírito de cólera e de vingança). É possível afirmar que na fala presidencial, quer seja em seu discurso proferido na ONU, quer seja nas suas apresentações cotidianas, inclusive no seu Twitter, o sentido de vingança, de retaliação, de raiva, apostando em sua permanência, como se esta nunca fosse acabar, são presentes e regem a forma, o ritmo e a inflexão da fala. Enfim, revestem o discurso de um véu invisível àqueles que têm a fumaça da ilusão nos olhos.

\section{OBSERVAÇÕES FINAIS}

"O verdadeiro democrata é aquele que, com meios puramente não violentos, defende sua liberdade, por conseguinte, a de seu país e, finalmente, a da bumanidade inteira".

Mahatma Gandhi

A análise do discurso presidencial proferido na ONU apresentado aqui é mais um exercício de mitocrítica para se buscar um direcionamento ou o sentido das propostas apresentadas por Bolsonaro, de modo a buscar uma compreensão acerca do nível de realidade elas se enquadram, uma definição de seus mitos reitores, na continuidade de seu governo. O que foi analisado diz respeito a esse período de nove meses. Foram encontrados os mitos reitores da ilusão e da morte, em seu discurso, na sua apresentação, enquanto presidente do Brasil, no seu ethos (caráter), encontraram-se "os espíritos da cólera e da vingança", o mito de Erínis. Na mitocrítica, os mitos podem mudar durante o período de duração de um fato analisado, ora convergindo para um mesmo ponto, ora divergindo. Somente na finalização do período é que se faz possível uma análise mais detalhada e definitiva.

Também é necessário ter em conta que os períodos sociais são cíclicos e que têm seus mitos reitores, que se revezam no predomínio dos períodos analisados. Essa tópica sociocultural é muito bem explicada por Durand (1996), que demonstra a oscilação de uma sociedade entre a sístole e a diástole, 
com uma duração mais ou menos rápida, não durando menos que uma geração e nem mais que um milênio. Nos movimentos míticos, um mito será vigente, enquanto outro será latente. Em um determinado momento, acontece a queda de um e a subida de outro, como se fosse um processo psíquico social, devido à baixa (abaissement) do nível mental, que permite o aparecimento dos complexos constelados em torno de um arquétipo. A sociedade se estrutura sobre dois mitos, sempre: um ascendente, que se esgota quando se institucionaliza, e outro que vive nas profundezas do $i d$, do inconsciente social, em estado latente, esperando o momento de seu surgimento.

Seguindo esse raciocínio, pode-se pensar, conforme Hillman (1997) aponta, que a semente podre do carvalho é necessária e representa a sombra psicossocial. Para o que aqui se propõe, essa sombra toma a forma do mito latente, posto que o mito anterior se institucionalizou e caiu. Nesse sentido, a fala do presidente não é de responsabilidade unicamente dele, mas de todos que, por qualquer motivo, elegeramno. É a fala de uma sociedade impregnada de raiva e vingança e de um sentido equivocado da palavra empreendedorismo - compreendida por muitos como sendo o progresso pessoal acima de tudo e de todos -, uma visão particularizada e perniciosa que faz parte, inclusive, das pessoas comuns e de seus anseios. Não importa comer comida envenenada, se se tiver um tostão a mais para gastar - o mal da classe média e medíocre. Neste sentido, Hillman (1997) e Durand (1996), trilhando caminhos diferentes, convergem e chegam a um mesmo sentido, na análise sociocultural. Se para um, o mito ascende após um período de tempo, para o outro, o mito revela a necessidade de um aprimoramento social, mesmo que esse mito represente o mal e exponha a propensão psicológica para a destruição, uma característica psicológica do ser humano. Esta tendência latente é o que protege as organizações políticas e as repressões morais, conforme Hillman (1997). Por algum motivo o mito da destruição subiu na tópica sociocultural brasileira. É assim que, ao analisar Hitler, Hillman (1997) aponta que um cidadão consciente ocidental não deve se esquecer do período de Hitler e do seu potencial demoníaco, e que essa virulência não precisa ressurgir. No entanto, o mito reitor que havia no Brasil, propiciou o aparecimento de um mito da destruição

O uso do prefixo des-, aqui, traz aspectos semânticos que apontam para a noção de des- arranjo, de des-harmonia, o que nos remete para a ideia de destruição, conforme aponta Couto (2003). "Em suma, o prefixo DES frequentemente indica algo ruim, associado a desfazer e destruir" (COUTO, 2000, p. 375). O prefixo re- em refazer, sugere que algo feito anteriormente foi desfeito, o que instaurou o caos. E ele acredita veementemente que é um salvador, enviado para restabelecer o cosmos. Entretanto, todo o seu discurso indica que ele faz justamente o contrário. Fortemente ajudado por seus filhos, ele contribui para fortalecer a polarização ideológica no Brasil, visível no "nós contra eles". Além disso, ele também defende o armamento da população, como se mais armas nas ruas significasse uma população mais segura. É uma miopia a toda prova. A ira e a vingança fortemente marcadas no discurso analisado são pensamentos e 
ações negativas que se contrapõe a todo um ideário de agregação, de conciliação que era defendido por Gandhi. Líder indiano, Gandhi avisava ao império britânico que dividir a Índia levaria à maior carnificina e foi exatamente isso o que aconteceu. Seria isso o que poderíamos esperar para o Brasil? Hillman (1997) diz:

[...] O psicopata bem-sucedido agrada o povo e se elege. O vidro grosso da tela da tevê e sua versatilidade camaleônica para exibir qualquer coisa que se queira favorecem a distância, a frieza e a fachada de charme, assim como favorece o aparato dos cargos de alto escalão na política, no judiciário, na igreja e nas grandes companhias. Quem quer que esteja em ascensão em um mundo que reverencia o sucesso deve ser suspeito, pois esta é uma era de psicopatia. O psicopata de hoje já não foge como ratos imundos pelos becos escuros dos filmes branco-e-preto de 1930. Ele desfila a bordo de limusines blindadas pelas avenidas em viagens oficiais, governa nações inteiras e envia delegados à ONU. O demoníaco atemporal, contudo, vem ao mundo em trajes contemporâneos, vestido para matar (HILLMAN, 1997, p. 230-231).

E assim, eis a sombra de uma Nação - a fala do eleito.

Entretanto, ainda há aqueles que buscam combater a destruição perpetrada pelo governo Bolsonaro. Em 2019, quando o presidente brasileiro pregava a destruição a Floresta Amazônica com fins meramente econômicos, a Igreja Católica se mobilizava para realizar o Sínodo dos Bispos, que teve como tema Amazônia: novos caminhos para a Igreja e para uma Ecologia Integral. Esse encontro abordou a riqueza dos saberes e da diversidade indígena e a necessidade de se defender a Amazônia e seus povos frente às constantes ameaças dos interesses econômicos em seus territórios. Em documento divulgado após o evento, a igreja externou a sua preocupação em relação a um ecossistema que está ameaçado.

É importante entender que as relações ambientais não ocorrem em paralelo à existência humana, como se uma não dependesse da outra. Os processos ecossistêmicos que colocam em risco a vida de milhares de espécies na Amazônia, também colocam em risco a vida de bilhares que seres humanos que habitam o planeta, pois, como Maturana (2001) bem apontou, “[o]rganismo e meio desencadeiam mutuamente mudanças estruturais sob as quais permanecem reciprocamente congruentes, de modo que cada um flui no encontro do outro seguindo as dimensões em que conservam sua organização e adaptação, caso contrário, o organismo morre" (MATURANA, 2001, p. 65). Ou seja, não é apenas a Amazônia que está em risco, é a espécie humana.

\section{REFERÊNCIAS}

BROWN, Lester. Eco-Economia. Rio de Janeiro: EPI - Earth Policy Institute / UMA - Universidade Livre da Mata Atlântica, 2003. 
CAPRA, Fritjof. As conexões ocultas: ciência para uma vida sustentável. Tradução: Marcelo Brandão Cipolla. São Paulo: Cultrix, 2003.

COUTO, Hildo H. do. A prefixação no crioulo guineense: desfazendo e refazendo ações. Revista internacional de linguística ibero-americana - RILI v. 1, n. 1, p. 161-174.

DURAND, Gilbert. Mito, Símbolo e Mitodologia. Tradução Hélder Godinho e Vitor Jabouille. Lisboa: Editorial Presença, s/d.

DURAND, Gilbert. Introduction à la mythodologie - mythes et sociétés. Paris: Albin Michel, 1996.

DURAND, Gilbert. Campos do Imaginário. Tradução: Maria José Batalha Reis. Lisboa: Instituto Piaget, 1998.

GREIMAS, A. J.; COURTÈS, J. [s/d]. Dicionário de Semiótica. Tradução: alceu Dias Lima; Edward Lopes; Maria José Castagnetti Sombra; Tieko Yamaguchi Myiazaki. $7^{a}$ ed. São Paulo: Contexto, 2008.

HILLMAN, James. O Código do Ser: uma busca do caráter e da vocação pessoal. Tradução: Adalgisa Campos da Silva. Rio de Janeiro: Objetiva, 1997.

KERÉNYI, Karl. A Mitologia dos Gregos - a história dos deuses e dos homens, v. I. Tradução: Octávio Mendes Cajado. Petrópolos, RJ: Editora Vozes, 2015.

LAFARGUE, Paul. 2019. A lingua francesa antes e depois da Revolução. Ecolinguística: revista brasileira de ecologia e linguagem (ECO-REBEL) v. 5, n. 1, p. 46-84. Disponível em: https://periodicos.unb.br/index.php/erbel/article/view/22807/20551

LEVIS, C.; COSTA, F. R. C.; BONGERS, F.; PEÑA-CLAROS, M.; et al. Persistent effects of pre-Columbian plant domestication on Amazonian forest composition. Science. Vol. 355, Issue 6328, pp.925-931, 2017.

MATURANA, Humberto R. \& VARELA, Francisco J. A Árvore do conhecimento: as bases biológicas da compreensão humana. Tradução: Humberto Mariotti e Lia diskin. São Paulo: Palas Athena, 2001.

MATURANA, Humberto. Emoções e Linguagem na Educação e na Política. Tradução: José Fernando Campos Fortes. Belo Horizonte, Editora UFMG, 2001.

MORIN, Edgar. O método 2: A vida da vida. Tradução: Marina Lobo. Porto Alegre: Editora Sulina, 2001.

ZIMMER, Heinrich. Mitos e Símbolos na arte e Civilização da Índia. Tradução: Carmen Fischer. São Paulo: Palas Athena, 1989. 


\title{
Title
}

Bolsonaro's discourse at the un in 2019: the strength of mitemas and the truth of myths.

\begin{abstract}
Present-day political and media discourses on the perception of the interactions between humans and the environment quite often contain fairly hidden overtones that are not always clear when it comes to sustainability and the planet's health. For this reason - and taking into consideration the fact that humans apprehend nature through symbols - the objective of this article is to discuss the way symbolic and mythical aspects are brought to the fore in order to construe the recurrent discourses about Amazonia. We'll analyze the discourse proferred by Bolsonaro during UNO's General Assembly in September 2019. The analysis, based on Gilbert Durand's mytocritics, points towards the founding myth of Maha-Maya, or simply Maya, the Hinduist goddess of Illusion, the goddess who creates the world together with Brahma. While Brahma creares the real, Maya crates the illusory and the dreams. The veil of illusion permeates the Brazilian president's discourse concerning what is new and the resurgence of Brazil. However, at the same time that resurgence and renaissance are looked for one can see that there is a sense of death, of what puts an end to life. In this case the god Antaka, an epithet of Yama - the god of death - comes up. The world must be destroyed in order to be reborn. Therefore, the president's discourse implies destruction due to a personal desire, far from the desire of the majority of the country's inhabitants. This myth unveils the Erinias, the third group of Grey Goddesses (beyond the Moiras and Greas). These were older than the gods that arrived with Zeus and had serpents in place of hair as well as dark skin. Their names were: Aleto (what never ends), Tisifone (retaliation), and Megera (rage). These goddesses can be invoked together by the name of Erinis (spirit of rage and revenge). In the present connection it is possible to say that there is a sense of revenge, retaliation and rage not only in the UNO's discourse but also in the president's everyday speeches.
\end{abstract}

\section{Keywords}

Imaginary; Political discourse; Mytocritics; Construction/Destruction; Environment.

Recebido em: 24/02/2020.

Aceito em: 19/03/2020.

Travessias, Cascavel, v. 14, n. 1, p. 121-139, jan./abr. 2020.

http://www.unioeste.br/travessias 